\title{
Perspectivas
}

ISSN-L: 2215-4728

DOI: http://dx.doi.org/10.15359/rp.23.1

http://www.revistas.una.ac.cr/perspectivas

N. ${ }^{\circ}$ 23. Julio-Diciembre, $2021 \cdot$ pp. 1-29

\section{¿Qué historia enseñar en las escuelas saluadoreñas en el 2021?}

What history to teach at salvadorean schools at 2021?

\author{
Josefa Viegas Guillem*
}

Fecha de recepción: 24/02/2021 • Fecha de aceptación: 10/04/2021

Resumen: Este artículo realiza una propuesta de ¿qué historia enseñar en El Salvador en el contexto de la conmemoración del Bicentenario de la Independencia? Para ello la autora aborda el tema en tres aspectos. El primero informa de las principales novedades del programa oficial de Estudios Sociales, los contenidos y recursos con los que cuenta el sistema educativo, en los últimos años, para enseñar historia. En el segundo aspecto se anuncian algunos resultados de una encuesta a diferentes personas de la comunidad educativa acerca de qué historia enseñar, con qué metodologías y a partir de qué valores. Por último, la autora realiza una propuesta personal y profesional desde el enfoque teórico de las competencias

\begin{abstract}
This article presents a proposal of what kind of history to teach in El Salvador within the framework of the bicentenary of the country's independence. In order to do that, the author uses a threefold approach. The first aspect informs about the main developments of the program, the contents and resources available in the education system to teach history. The second aspect refers to some of the results of a survey with different members of the educational community regarding what kind of history to teach, what methodologies to use and what values are at the base. Lastly, the author presents a personal and professional proposal using the socioformative competences theoretical framework on what kind of history to
\end{abstract}

* Española, residente en El Salvador. Licenciada en Historia por la Universidad de Valencia, Valencia, España. Docente en la Licenciatura en Historia de la Universidad de El Salvador (UES), Sede Central, San Salvador, El Salvador. josefa.viegas@ues.edu.sv. ORCID: https://orcid.org/0000-0003-4653-2769. 
socioformativas en relación con qué historia enseñar, presentando una Caja de Herramientas Didácticas titulada “200 años en tus manos" para estudiantes de Tercer Ciclo Bachillerato.

Palabras claves: ciencias sociales; El Salvador; Enseñanza de la historia; Enseñanza de las ciencias sociales; Historia, América Latina; innovación pedagógica.

\section{La historia es el producto más peligroso que haya elaborado la química del intelecto humano. Sus propiedades son muy conocidas. Hace soñar, embriaga a los pueblos, engendra en ellos falsa memoria, exagera sus reflejos, mantiene viejas llagas, los atormenta en el reposo, los conduce al delirio de grandeza o al de persecución, y vuelve a las naciones amargas, soberbias, insoportables y vanas.} Paul Valéry

\section{Unas palabras introductorias}

Llegamos al 2021 y a la conmemoración esperada de los doscientos años de vida independiente en una situación que no esperábamos, en el contexto de una pandemia que ha socavado las bases más profundas de la economía y de la política.

El calendario marcará doscientos años de un hecho que la historiografía ha tratado de explicar desde distintos puntos de vista y que la política nacional de El Salvador y de los demás países centroamericanos ha capitalizado como el momento fundacional del Estado nación y de su legitimidad, con el apoyo de la educación como espacio privilegiado de difusión. Historiografía y política educativa no siempre van de la mano; sin embargo, frente a la conmemoración bicentenaria, ambas vías confluyen en la necesidad de rememorar. Esta mirada hacia el pasado es de obligado cumplimiento para explicar un presente complejo que implique un impulso para visualizar un futuro más halagüeño como país, y, por supuesto como región.
La escuela ha sido y es fundamental para la divulgación de la historia nacional o no, y de sobra conocida su influencia para la conformación de las conciencias ciudadanas, nacionales, de relaciones internacionales como el eurocentrismo (Ferro, 1993). Por ello, es fundamental responder a la pregunta propuesta desde la revista Perspectivas acerca de ¿qué historia enseñar en El Salvador en este contexto de conmemoración?

La Independencia es conmemorada cada 15 de septiembre con diferentes eventos y rituales diversos que se relacionan más con la llamada "religión cívica" del Estado. Son de obligatoria ejecución los desfiles cívico-militares, el cierre de calles para que cientos de estudiantes y militares las recorran en ciudades y pueblos, discursos acartonados sobre el evento de la Independencia, donde se repiten fechas y datos sin cuestionamiento. El balance de las horas dedicadas a la "conmemoración" de la Independencia anualmente se llena de ensayos para desfilar, de forma adecuada, según la lógica militar, memorizar oración a la bandera y cantar el himno nacional. En realidad, no existe el espacio para la reflexión de un hecho histórico tan fundamental. Como en otros lugares, la enseñanza y conmemoración de la Independencia es un ejemplo del uso público y político del pasado.

En primer lugar, realizaremos una breve trayectoria de la enseñanza de los contenidos históricos del Ministerio de Educación de E Salvador. Después resumiremos las opiniones de diversas personas integrantes de la comunidad educativa acerca de ¿qué historia enseñar en este contexto de celebración y conmemoración? Por último, realizaré una propuesta personal y profesional como especialista en la enseñanza de la historia.

\section{La historia en el contexto educativo salvadoreño}

Las nuevas propuestas teóricas y metodológicas plantean que la historia no se enseñe como un fin en sí misma sino como un vehículo para el desarrollo de competencias de análisis, sentido crítico y de reflexión de la sociedad misma y de su pasado, competencias ciudadanas como, por ejemplo, la educación para la paz. Estos aspectos tienen consecuencias en la selección de los contenidos, así como su gradación en el sistema educativo. La pregunta “¿qué historia enseñar?” ha sido sustituida 
por “¿qué competencias para la vida se adquieren cuando enseño la historia?" cuestiona si la historia debe ser un instrumento para la formación de la identidad o una escuela de ciudadanía. Opta por la segunda opción: "la enseñanza de la historia no debe tener como finalidad la instauración, conservación o profundización en la identidad nacional y en la ideología nacionalista, sino que debe convertirse en instrumento fundamental para que las nuevas generaciones ganen capacidad de análisis y control sobre el funcionamiento de la sociedad, la cultura y la cosa pública". Rosa (2004, p. 64). Este cambio, también ha significado una respuesta contundente frente a la amenaza permanente de la carencia de aplicación concreta de la historia en el entorno inmediato e incluso en práctica de la ciudadanía. En este sentido, el cambio fundamental del aprendizaje de la historia hacia una experimentación de competencias ciudadanas está siendo similar en otros lugares de América Latina como una práctica habitual del enseñar y aprender. (Ayala, 2018; Memoria, 2016)

Los nuevos planteamientos educativos con enfoque constructivista y la formación por competencias educativas ofrecen nuevos retos a los equipos docentes que enseñan historia, desde el punto de vista curricular en primera instancia hasta la didáctica y la evaluación al final del proceso. Desde un enfoque socioformativo, las secuencias didácticas según Sergio Tobón (2010) se conciben como: "actuaciones integrales ante actividades y problemas del contexto, con idoneidad y compromiso ético, integrando el saber ser, el saber hacer y el saber conocer en una perspectiva de mejora continua" (p. 11).

La práctica habitual del enseñar y el aprender historia ha consistido, tradicionalmente, en la memorización y repetición de datos, fechas y nombres. Los libros de texto utilizados en las aulas plantean ese mismo esquema de enseñanza-aprendizaje en el que los estudiantes muchas veces copian textos y memorizan cronologías. En este sentido, el principal objeto de aprendizaje eran los contenidos de primer orden. En los últimos años se ha puesto mayor énfasis en el aprendizaje del "pensar históricamente", es decir, de la adquisición de competencias analíticas y críticas que permitan al estudiantado una relación con el conocimiento histórico más parecido a su elaboración que a su producto final (Carretero \& Voss, 2004; Gómez, Ortuño \& Molina 2014).
En el sistema educativo salvadoreño, ${ }^{1}$ desde 1996 , la historia se inserta junto con otras ciencias sociales en la asignatura Estudios Sociales y Cívica. En las escuelas los libros de texto son gratuitos, los cuales han sido formulados y revisados por el Ministerio con apoyo de distintas agencias de cooperación internacional. Desde enfoques más tradicionalistas se está transformando el currículum hacia la enseñanza-aprendizaje por competencias, bajo el enfoque socioformativo al que nos hemos referido con anterioridad, lo cual complica el enfoque teórico y la metodología didáctica a docentes que, en la mayoría de los casos, acceden en su propia formación a cátedras con similares componentes didácticos.

Por otra parte, la asignatura de Estudios Sociales, y en específico, la historia suele asociarse a una falta de interés y con cierta apatía en la que el estudiantado está condenado a un papel pasivo y repetidor de datos.

Desde hace algunos años ha habido proyectos promovidos por el Ministerio de Educación de El Salvador que han tratado de transformar la educación pública apostando a la formación docente. Por vez primera, después de muchas décadas, el profesorado ha estado en el centro del interés. En ese sentido, se han alternado investigaciones que buscan conocer las condiciones en las que los formadores están aprendiendo la teoría y la práctica del enseñar en las universidades del país, pero también quién capacita y de qué manera al profesorado existente en las aulas ministeriales (González \& Avelar, 2019). A la par de ello, se inició un programa que requirió de una estrategia y planificación nacional para la actualización docente llamado "Programa de Desarrollo Profesional Docente, formación inicial y formación continua”. En específico, con la formación especializada en Estudios Sociales profesores universitarios en Historia, Antropología, Filosofía y Sociología diseñaron e impartieron módulos de formación para una selección de mejores maestras y maestros, para formarlos como "especialistas" en Estudios Sociales de un ciclo formativo (primaria y media). Posteriormente, estos mismos especialistas formaron en jornadas más reducidas a otros grupos del profesorado nacional repartidos por zonas geográficas. Esta formación

1 El sistema educativo salvadoreño mantiene como obligatorios los tres ciclos de la Educación Básica, de tres años de duración cada una. El Primer Ciclo $\left(1 .^{\circ}, 2 .^{\circ}\right.$ y $3 .^{\circ}$ grado), Segundo Ciclo $\left(4 .^{\circ}, 5^{\circ}, 6^{\circ}\right)$ y Tercer Ciclo $\left(7 .^{\circ}, 8 .^{\circ}, 9^{\circ}\right)$. La educación media comprende el Bachillerato General que tiene como duración dos años o el técnico, al que se le añade un año más.

¿Qué historia enseñar en las escuelas salvadoreñas en el 2021? 
docente fue desarrollada en diversas áreas del conocimiento, correspondientes a las diferentes asignaturas impartidas, y también hubo una clasificación por ciclos. La especialidad en los Estudios Sociales tuvo una formación específica para primaria y otra para media. Incluye contenidos de historia de El Salvador, geografía crítica, teoría social, antropología y otros). Por otro lado, la formación y actualización a profesoras y profesores hizo énfasis en las metodologías novedosas de las ciencias sociales.

Se ha capacitado más de 30000 profesoras y profesores mediante este programa de formación docente ${ }^{2}$ y que significa el $62 \%$ de la planta docente nacional (Memoria, 2019, p. 22; Memoria 2020, p. 96). Aunque el resultado tiene algunos puntos de discusión, no cabe la menor duda de que es el programa más extenso en este rubro y, que ha permitido que el conocimiento más innovador de cada especialidad haya llegado directamente al sector docente. También ha posibilitado que muchas maestras y maestros, ya especialistas en su tema, hayan participado en otros programas de consulta, de investigación o de formación replicantes del mismo programa.

Otro punto fundamental de las novedades ocurridas en los últimos años ha sido la revisión de programas de estudio y la escritura de guías de aprendizaje, en forma de libros de texto, de las cuatro materias fundamentales de la formación en primaria y secundaria. En el caso de Estudios Sociales este proceso todavía está en camino de llegar a su fin. En realidad, ha sido un proceso que comenzó con la evaluación de los contenidos de los programas y la propuesta de nuevos. En primaria se reorganizaron algunos contenidos.

En el caso de Tercer Ciclo y Bachillerato están modificándose, con el fin de relacionarse con los nuevos enfoques socioformativos. En este sentido, se repensaron los contenidos, se plantearon competencias fundamentales y, en este momento, se están redactando guías de trabajo acordes.

Los enfoques socioformativos se han apoyado en el aprendizaje de las capacidades ciudadanas del sistema educativo, el enfoque de derechos,

2 A fecha de 2018, según la Memoria de Labores del Ministerio de Educación, se habían formado 22973 para el 2019 (Memoria, 2020); a los que se suman los 3345 docentes de años posteriores (Memoria 2020).

la ciudadanía, así como la historia de sus concepciones y prácticas para un abordaje de la democracia en El Salvador (Ramis \& Rodríguez, 2018)

Estas iniciativas han sido ideadas y diseñadas en el centro de la institución gestora de la educación formal en El Salvador, el Ministerio de Educación y, en su seno se formó, en el 2018, una entidad más autónoma llamada INFOD, el acrónimo de Instituto Nacional de Formación Docente, donde se han gestado diversidad de proyectos de investigación y de aplicación de la educación. A partir de ella se organizaron y sistematizaron las tareas de investigación educativa y, sobre todo, de formación docente, que anteriormente estaban diseminadas en distintas instancias en el mismo ministerio.

\section{La comunidad educativa opina acerca de qué historia enseñar/ aprender}

Con la intención de abrir las opiniones se consultó a otras personas de la comunidad académica y educativa en general. Mediante las distintas oportunidades que nos está generando la tecnología fueron consultadas personas de tres diferentes grupos: académicos especializados en la historia, a maestras y maestros y, por último, equipo de trabajo del Ministerio de Educación y del Ministerio de Cultura.

La encuesta consistió en tres preguntas de contestación libre y fue enviada por diferentes medios digitales. Las tres preguntas abiertas de la encuesta fueron las mismas para todos los participantes, fueron estas:

1. ¿Qué historia (hechos, procesos, protagonistas) necesitamos enseñar en las escuelas o institutos en el contexto de la celebración del Bicentenario de la Independencia Centroamericana?

2. Para la enseñanza de estos contenidos ¿qué actividades/estrategias/metodologías serían las más apropiadas para niñas, niños y adolescentes?

3. Qué valores fundamentales deberían transmitirse a estas generaciones en las clases de historia? 
Presentamos el resumen de hallazgos en Profesionales de la historia, Personal ministerial y Maestras y maestros.

\section{Profesionales de la historia}

Por lógica, el gremio académico ${ }^{3}$ abunda en detalles y complejidades del proceso histórico de la Independencia y la principal propuesta radica en proponer una interpretación más global, diversa, desde el punto de vista social y étnico.

En este sentido, por su extenso conocimiento de primera mano de los contenidos históricos, este grupo de académicos promueven una articulación de elementos para abordar la complejidad social, política y étnica de la interpretación de la Independencia. En primera instancia, lo que cabe señalar es la apuesta por el enriquecimiento de la interpretación, donde se abona en conjugar los procesos más globales con los más locales hasta llegar a los individuos. En este sentido, se llama a la comprensión de la Independencia en el de las Revoluciones Atlánticas, en un contexto de Reino de Guatemala, y en el significado de la crisis de la Corona española y las discusiones y prácticas en torno a la Constitución de Cádiz para los movimientos independentistas o la importancia fundamental de las ideas de la Ilustración y, de su transmisión, por el significado de quiebre en el momento.

Por lo tanto, se apuesta por una mirada de las grandes corrientes políticas, económicas, sociales y culturales que impactan en unos individuos que tienen nombres y apellidos. Por lo tanto, se alejan de las propuestas interpretativas más cercanas a la llamada historia de bronce, que ha insuflado las energías nacionalistas y que ha asimilado a los próceres como abanderados superhéroes. En este sentido, más que abonar a la profusión de datos Xiomara Avendaño, catedrática de Licenciatura en Historia de la Universidad de El Salvador, propone un listado de ocho temas o conceptos a través de los cuales comprender estas dinámicas del contexto: ciudadanía, el voto, opinión pública, organización, movilización política, abolición de la esclavitud, Estado salvadoreño, veladas. (Comunicación personal, 1 de febrero de 2021).

3 Mis agradecimientos a colegas (y amigos) por su participación en la encuesta: Dra. Xiomara Avendaño Rojas, Dra. Eugenia López., MSc. Alfredo Ramírez., Lcdo. Leonel Hernández, Dr. Héctor Lindo-Fuentes.
La propuesta radica también en la no eliminación de estos protagonistas sin involucrarlos en la interacción social con otros sujetos como mujeres, mestizos, mulatos, indígenas. La propuesta de Alfredo Ramírez, catedrático y actual coordinador de la Licenciatura en Historia de la Universidad de El Salvador, va en este sentido "Las élites pudieron haber tenido una interpretación de la independencia (Sociedad de Amigos del País, Universidad de San Carlos) pero también hay otras interpretaciones de las clases subalternas, como nos indica el movimiento de Anastasio Aquino por ejemplo" (Comunicación personal, 2 de febrero de 2021).

Aunque la mayoría son propuestas de interpretación para Eugenia López, catedrática de la Licenciatura en historia de la Universidad de El Salvador, también es importante el cuestionamiento de los mitos, como, por ejemplo, la definición del movimiento del 5 de noviembre de 1811 como Primer Grito de Independencia o el uso en sí mismo del calificativo de «independentista», que es una parte fundamental de la historiografía tradicional patriótica.

Se aduce la necesidad de la investigación histórica como imprescindible y necesaria.

Las propuestas desde el punto de vista metodológico son menos profusas y detallistas, pasan por el énfasis en los documentos y otras fuentes primarias. Para Leonel Hernández, profesor universitario de Historia en la Universidad Centroamericana "José Simeón Cañas", además de consultor en educación en otros niveles no universitarios, plantea la necesidad de diferenciar por edades y apoyarse en el enfoque constructivista y socioformativo que propone hacer al estudiantado, de forma tal que este genere un pensamiento crítico a partir de actividades creativas y de nuevas tecnologías.

Los valores fundamentales a los que apunta el gremio académico se derivan directamente del conocimiento del proceso histórico. Destaca la ciudadanía, como uno de los aspectos esenciales de la democracia (Héctor Lindo, profesor emérito de Historia y Estudios Latinoamericanos en la Universidad de Fordham, Nueva York, Estados Unidos de América), la igualdad entre todos los seres humanos a partir de los derechos humanos. Pero, también, se reitera la idea de diversidad como una sociedad multiétnica y multilingüe (Xiomara Avendaño). Se pone de 
manifiesto el énfasis entre la igualdad política y la diversidad cultural, social, étnica, genérica. En este sentido, se enfatiza la reflexión sobre la inclusión específica de las mujeres, así como indígenas, mulatos, para comprender y apreciar la Independencia desde el presente. Recalcan también algunos aspectos de la conformación y funcionamiento del Estado como la separación de poderes que se equilibran entre sí o la separación entre la Iglesia y el Estado. Aparece como un valor fundamental la autonomía política de las naciones como novedad y producto del mismo proceso histórico, pero también la libertad individual y el surgimiento del derecho individual. Un aporte novedoso de Xiomara Avendaño es la negociación como elemento fundamental de la dinámica política y social. "Suele abordarse el conflicto, pero pasa desapercibida la capacidad de diálogo de los grupos humanos. El levantamiento del 5 de noviembre de 1811, terminó con acuerdos (guste o no)" (Comunicación personal, 1 de febrero de 2021).

Por último, para Leonel Hernández, estos aspectos deben quedar integrados a partir de las competencias ciudadanas del programa del Ministerio de Educación.

\section{Personal ministerial}

Tres personas que laboran en el Ministerio de Educación y el Ministerio de Cultura ${ }^{4}$ contestaron la encuesta de las tres preguntas referidas a la enseñanza de la Historia. Por el momento ninguno de ellos conoce los planes concretos de conmemoración de la efeméride, ni a corto ni a medio plazo, al menos para el Ministerio de Educación, aunque sí han desarrollado líneas concretas en cada una de las áreas que tienen a cargo. En el caso del INFOD, del Ministerio de Educación, desde hace un tiempo que se han venido desarrollando investigaciones publicadas para profundizar en el conocimiento del Bicentenario. Como novedades se plantea que las competencias históricas partan desde la primera infancia hasta el bachillerato.

4 Carlos Rodríguez, coordinador del INFOD (Instituto Nacional de Formación Docente) y Director Nacional de Formación Docente, ambas instancias del Ministerio de Educación. Miguel Angel Agular, Técico I Depto de Curríulo, Educación Media del Ministerio de Educacion. Eic Doradea, Director Nacion de Bibliotecas, Archivos y Publicaciones del Ministerio de Educación.

Por otro lado, la coyuntura vivida en el momento está suponiendo una tensión política en ascenso permanente, entre pasado y presente, ya que existe un debate en el ámbito público acerca del significado de los Acuerdos de Paz en El Salvador de 1992. "Hay una disputa de dos narrativas: derecha e izquierda. Estamos fragmentados, y esto tiene un reflejo en el aula. Es necesario construir una narrativa histórica desde las víctimas. Esto es un consenso a partir del cual vamos a trabajar" (Rodríguez, C., comunicación personal, 1 de febrero de 2021).

Coinciden con Miguel Ángel Aguilar, en la necesidad de realizar una revisión del caminar de 200 años, es decir, una visión diacrónica. Aunque este último incide en temáticas propias de la historia de la educación formal, o la construcción de los símbolos en la misma República, así como del papel activo de indígenas.

Eric Doradea, desde el Ministerio de Cultura manifiesta apostar por la necesidad de «una historia descolonizadora, y un no a la historia del bronce». Desde la Dirección de la que está a cargo, ha promovido la publicación de libros y revistas en el marco del análisis de los 200 años de vida republicana salvadoreña que están en curso de preparación. Promueve además propuestas didácticas de acercamiento a la primera infancia desde la música, la tradición oral y la oralidad, la lingüística y las danzas tradicionales propias de El Salvador.

Entre las metodologías apropiadas para enseñar esta historia se destaca el papel de la tecnología, fundamental en estos tiempos, cuando las clases se están realizando a distancia, con la incorporación de imágenes, videos, libros y revistas.

En cuanto a los valores fundamentales a enseñar en este contexto se repiten los relacionados con la ciudadanía y su práctica: derecho de participación y elección, rescatar la diversidad y la pluralidad de la sociedad salvadoreña de todos los tiempos. Aunque también aparecen otros, propios de la práctica del Estado, como la rendición de cuentas y la corrupción.

\section{Maestras y maestros}

Se consultó a diferentes personas del gremio docente y contestaron la encuesta por diferentes medios, finalmente once; por lo tanto, este ejercicio ha de verse como una mera muestra de opinión, sin intención

¿Qué historia enseñar en las escuelas salvadoreñas en el 2021? 
de ser un análisis cuantitativo. De estos docentes, una es especialista en pedagogía y ha laborado en distintas formaciones docentes; otra persona es directora de una institución educativa privada y bilingüe, siete son docentes del ámbito público y el resto docentes de colegios privados.

Hay algunos rasgos que vale la pena resaltar como un común denominador.

En relación a la primera pregunta, las personas formadoras optan por una versión extensa en el tiempo o diacrónica del proceso histórico salvadoreño, incluso eligen abarcar «toda la historia», incluso más allá de los doscientos años de vida republicana, desde la conquista española del territorio y del mundo prehispánico. Aparecen referencias a los mitos comunes en la historia enseñada de El Salvador, como el ensalzamiento nacionalista del Primer Grito de Independencia, la mitificación de la población indígena o la heroización de los próceres. Pero también, en cuatro de las encuestas, aparece la idea del poco conocimiento y consideración que se tiene del pasado en la escuela y, en general. Aparece la necesidad de identificar las protagonistas femeninas en cinco de las encuestas.

Es interesante recalcar que algunas de las contestaciones mantienen la idea de que existe una historia "de verdad" o que permanece escondida, distinta de la oficial.

Sin embargo, hay dos personas de este rubro de encuestas contestadas por docentes que recibieron la Especialización del INFOD del Ministerio de Educación en Estudios Sociales y se observa una mayor profundización en los contenidos históricos y, en especial, los referidos al proceso de la Independencia, donde está clara la influencia de lecturas más académicas y cercanas a la primera línea de investigación.

En cuanto a las metodologías, son mucho más ricas y diversas que las planteadas por las personas de la academia y del Estado, ya que se plantean la realización de juegos de roles, dramatizaciones, videos, poemas, análisis de imágenes, etc. Lo cual sugiere la valoración de las metodologías que comparten aspectos de las ciencias sociales con el arte. Surge el planteamiento de adaptar a las distintas edades de niñas, niños y adolescentes, pero desde la integración del alumnado en el proceso de enseñanza-aprendizaje.

Por último, llama la atención que el principal valor que aparece es el respeto (en 10 encuestas), seguido de versiones parecidas de amor a la patria (valoración de lo propio, identidad nacional, orgullo por las tradiciones y costumbres del país). Después se entrelazan la tolerancia, la generosidad y la verdad, valores que están muy cercanos al plan de valores ministerial y se derivan menos de los procesos históricos a los que se refieren en la pregunta 1. Es bastante obvio que para el personal docente un corpus de valores más allá de la enseñanza de la historia sino un canal más para la educación.

\section{Niñas, niños y adolescentes}

Por último, como muestra exploratoria de la opinión del estudiantado se realizaron 24 entrevistas, de igual manera aprovechando las múltiples posibilidades de la tecnología y se adaptaron las preguntas para un vocabulario adaptado. Las entrevistas se realizaron a través de sus docentes, quienes enviaron las respuestas. La mitad de estas entrevistas se realizaron a niñas y niños provenientes de escuelas públicas, mientras que la otra mitad provienen de colegios privados.

Los hallazgos son interesantes. En primer lugar, destaca que la totalidad de las niñas, niños y adolescentes entrevistados no conocen que en este año se conmemora el 200 aniversario de la Independencia, a pesar de la rotundidad de la fecha. En segundo lugar, en cuanto se pregunta la cuestión acerca de los intereses propios por la historia en este contexto, destaca el énfasis que la gran mayoría del estudiantado pone en conocer el proceso de independencia, pero preguntan por sus protagonistas, a quienes reconocen como los próceres (ML, EE,), o por el Primer Grito de Independencia, uno de los referentes de la conformación nacionalista en el país; o las causas y consecuencias (NH). También es evidente la carencia de información y de explicación de un proceso fundamental y con una ritualización que incluye desfiles, disfraces, representaciones en el ámbito público. De hecho, hay un reconocimiento al respecto e incluso un desinterés por la historia, o la afirmación de que la historia cuesta aprenderla, ««no me gusta la materia 〉 (FD y CD) o no me interesa (DD). Llama la atención que, al contrario de los otros grupos, solo a dos niñas les interesa, en específico, el papel de las mujeres en la historia (VR, NP), y otra “ ¿cómo era en la colonia los esclavos?” (DH). Les interesa saber cómo eran las personas cotidianas, del día a día "porque nadie da detalles" (KD) o "nunca me lo ha respondido la maestra" 
(VT). Los temas de interés se amplían desde los mayas, o la historia prehispánica en general; la conquista, la llegada de "Cristóbal Colón en su barco" (BB). Se hacen preguntas tales como, ¿cómo se fundó el Salvador? (GB), o ¿cómo se descubrió? (EP).

Las metodologías de aprendizaje que proponen son diversas; desde las que parecieran cercanas a su cotidianidad como realizar mapas, carteles, trabajos de investigación de información o trabajos en grupo; a otras más dinámicas como ver películas, videos, o jugar en videojuegos, el uso de aplicaciones como Kahoot o Quizzy (VR), incluso algunos muy específicos de sus propios intereses "creación de cuentos situándonos en el pasado y nosotros como parte del proceso de independencia. Diferentes expresiones artísticas como la creación de poemas, dibujos o pinturas" (SR); que alguien llegara a dar una charla $(\mathrm{DH}, \mathrm{NH})$ o salir a conocer El Salvador (EP). También han contestado la pregunta con las actividades que no quieren que sucedan como "que no sean aburridas ni tediosas" (AE), que no sean de "copiar toda la pizarra en el cuaderno" (MD), o que "no sea de memorizar muchas fechas porque se distorsiona el mensaje" (AE) o como dice LD "de cualquier manera, pero con clases presenciales porque se aprende mejor".

Por último, con las respuestas a la pregunta 3 acerca de los valores que enseñan en su vida cotidiana estos contenidos históricos, las niñas, niños y adolescentes contestan con base en el calendario de valores del ministerio, el que más se repite es el respeto en 10 ocasiones. Aparecen otros como la integridad (RH) y el cuidado del planeta (EP), perseverancia y solidaridad (ML), amabilidad y ayuda a los demás (NP). Otras contestaciones se acercan a la aplicación más inmediata de los contenidos históricos como la empatía, la admiración por las personas del pasado, (DH), la conciencia del pasado (SR), patrimonio cultural (MS), igualdad y la justicia (EE, VT). También, aparece como valor en sí mismo el conocimiento, como cultura general (SP, AE, BB). Llama la atención también la referencia a cierto hastío del aprendizaje de los valores porque "es aburrido ver todos los años lo mismo" (AE).

\section{Una propuesta concreta de enseñanza de la historia: Caja de} herramientas didácticas Bicentenario

En este apartado realizaremos una contestación a la pregunta que motiva este monográfico de la revista Perspectivas, en relación a ¿qué historia enseñar en el contexto del Bicentenario? Presentamos una propuesta, en concreto, de materiales educativos elaborados para la conmemoración del Bicentenario en las escuelas, llamada Caja de Herramientas Didácticas: 200 años en tus manos.

La propuesta que presentamos a continuación fue un encargo del Instituto Nacional de Formación Docente, INFOD del Ministerio de Educación, como parte de la Colección Bicentenario. Esta Colección Bicentenario es un proyecto editorial que pretende una reflexión crítica, la investigación histórica y el pensamiento pedagógico de cara a la conmemoración y, que abarca desde diferentes perspectivas la sociedad, la cultura, la política y la economía de la vida republicana en estos primeros dos siglos.

De esta manera nació Caja de Herramientas Didácticas Bicentenario 200 años en tus manos ${ }^{5}$ que reúne las indicaciones solicitadas por el equipo directivo del INFOD del Ministerio de Educación. La idea de trabajar mediante caja de herramientas didácticas significa una continuación de una propuesta metodológica ya existente, paralela y en diálogo con los programas, libros de texto, guías metodológicas existentes (Ramírez-Barat, 2018)

Esta caja de herramientas se une a esta colección con el reto de promover aprendizajes significativos mediante estrategias pedagógicas que motiven el interés de niños, niñas y adolescentes en el estudio de la historia. En primer lugar, para superar los modos tradicionales en que se imparten los contenidos históricos. De esta manera, ser partícipes conscientes y reflexivos de todas y cada una de las acciones que se tejen para construir un nuevo futuro.

La metodología planteada pretende la comprensión de los contenidos a partir de metodologías innovadoras y diversas. En cuanto a

5 La Caja de Herramientas Didácticas Bicentenario está en este momento (febrero, 2021) en proceso de edición para su publicación virtual y física. La autoría es compartida con Vinicio Ramírez (historiador), Karen Rosales (asesoría pedagógica).

¿Qué historia enseñar en las escuelas salvadoreñas en el 2021? 
contenidos, lo más llamativo es la visión diacrónica de estos. Además, ofrece una posibilidad real de conmemoración del Bicentenario desde valores cívicos e identitaria, pero también, desde la visión crítica del pasado.

\section{Temáticas}

Se plantearon como problemáticas a desarrollar y que en realidad son considerados como grandes hitos sobre los cuales poder comprender a El Salvador. Estos ejes temáticos están relacionados con la consideración de la historia-problema más que a la narración de acontecimientos. Los ejes temáticos expuestos, de forma breve, fueron la independencia como proceso histórico, la configuración del Estado salvadoreño, derechos y ciudadanía, acuerdos y conflictividad, desigualdad socioeconómica, relaciones mujeres-hombres, etnicidad, demografía, economía de agroexportación, economía industrializada, economía de servicios y comercio, medio ambiente y geografía, religiosidad, patrimonio histórico, localidad y, por último, expresiones artísticas.

\section{Estrategias de aprendizaje}

Las estrategias de aprendizaje propuestas son parte de una selección de actividades comunes y similares a las realizadas por profesionales del área de ciencias sociales como: anotaciones en diario de campo, toma de fotografías, revisión de documentos, realización de entrevistas hasta la investigación histórica de hechos del pasado, mediante el análisis e interpretación de aspectos económicos, sociales, políticos, culturales, entre otros, según el desarrollo psicológico y social a quien vayan dirigidas.

También, es importante resaltar la inclusión del arte dentro de las actividades propuestas, pues, se considera como parte integral del desarrollo del ser humano. Consciente de ello, la UNESCO propuso en la XXX Conferencia General (Actas, 2000, p. 74), promover la inclusión de disciplinas artísticas en la formación general de niñas, niños y jóvenes por considerar que la educación artística contribuye al desarrollo de su personalidad, en lo emocional y en lo cognitivo, tiene una influencia positiva en su desarrollo general, en el académico y en el personal, inspira el potencial creativo y fortalece la adquisición de conocimientos, estimula las capacidades de imaginación, expresión oral, la habilidad manual, la concentración, la memoria, el interés personal por los otros, incide en el fortalecimiento de la conciencia de uno mismo y de su propia identidad; se proporciona a niñas, niños y adolescentes instrumentos de comunicación y autoexpresión, y, por último, contribuye a la creación de audiencias de calidad que favorecen el respeto intercultural.

Es precisamente, a través de algunas herramientas propuestas que el estudiantado podrá canalizar sus emociones, sentimientos y percepciones de lo que se le presente y descubra, a través de las diferentes expresiones artísticas: dibujo, pintura, modelaje, danza, música, etc. A la vez, que puede hacer partícipes a otros sectores de su institución educativa y a diferentes actores claves de la comunidad a la que pertenece. Para ello, se ha tenido en cuenta la necesidad del estudiante motivado, con capacidad de interactuación continua con su aprendizaje mediante la entrega de un producto terminado y significativo, con capacidad reflexiva y que incluya actividades de evaluación de autorregulación (Valle, Núñez, Rodríguez \& González, 2002, pp. 134-135).

Por otra parte, se asume un enfoque de enseñanza que rompa los esquemas de la enseñanza de la historia de la forma tradicional, es decir la memorística, con numerosos contenidos y una presentación de contenidos segregados. Para pasar a uno, en que, si bien los datos y hechos son importantes, su memorización no será el objetivo principal, sino más bien permitirá situar en contexto y orientar la lectura de la narración histórica. A la vez, se pretende no saturar al estudiantado con diferentes contenidos y en forma segmentada, sino desarrollar los contenidos a partir de problemas o situaciones, analizándolos desde diversas perspectivas y haciendo uso de los procesos de análisis que se emplean en la historia, tales como: multi-causalidad, empatía histórica, comparación, análisis de fuentes primarias de diversa naturaleza.

Se ha priorizado el uso de fuentes primarias mediante una selección de diversos tipos (documentos escritos, fotografías, mapas, música objetos fotografiados, la oralidad) que permiten reproducir la metodología de investigación histórica y desarrolla el análisis social. (Iturrate, Bardavio, Bou \& Pérez, 1996). Además, se realizará un especial énfasis en la comprensión del tiempo social y del tiempo histórico, más allá del ordenamiento de acontecimientos cronológicos; por ejemplo, a través de conceptos como cambio, continuidad o permanencia, ucronía, anacronía. 
En cuanto al manejo de la información, la metodología permite poner sobre la mesa diferentes fuentes de información, para que las niñas, los niños y adolescentes las reflexionen e interpreten, situándose en el contexto en que se desarrollaron, siendo empáticos con las personas claves que se mencionan y considerando la línea de quien la escribió, para romper así el manejo unidireccional de la historia, en donde, se ofrece una narrativa histórica acabada y tendenciosa. Como resultado del análisis crítico de diversas fuentes, el ejercicio de empatía histórica y la reflexión sobre temas del pasado, presente y futuro, se desarrolla una conciencia histórica en el estudiantado, que sirve de insumo para el desenvolvimiento de capacidades ciudadanas y productivas, para la escritura científica que adopta un compromiso social desde su rol en la sociedad.

\section{Estructura}

La estructura de la Caja de Herramientas se dispone en tres grandes partes con el fin de otorgarle un orden en la disposición de las herramientas didácticas, en relación con su significado en el tiempo. De esta manera, la Parte I corresponde a las herramientas didácticas que pretenden conocer el proceso histórico de la Independencia. Se le ha nombrado como "El pasado" y bajo el subtítulo de "Conocer los hechos". En este sentido, estas herramientas permiten aproximarse a la comprensión multicausal de la Independencia. Se asume, además, como el hito fundacional del itinerario particular de El Salvador, del Estado nación pero alejándose de la interpretación de héroes y próceres.

La Parte II se le ha titulado "Doscientos años de historia" y tiene como subtítulo: "El presente. Visión diacrónica". Recoge las actividades didácticas sobre diferentes temáticas con una visión diacrónica, es decir, que revisen en la larga duración los 200 años de vida independiente de nuestro país.

La Parte III de la Caja de Herramientas tiene por título "Mirando hacia el Tricentenario". Tiene como subtítulo "El Futuro. Conciencia histórica-responsabilidad individual y colectiva". Esta última parte contiene propuestas didácticas que promueven y guían la introyección de la responsabilidad individual y social de cada una de las personas salvadoreñas en el quehacer social, así como la conciencia acerca de la participación histórica hacia el futuro. Las herramientas propuestas también buscan la cooperación colectiva con un fin común, que implica la colaboración de toda la comunidad educativa.

En este sentido, la disposición tripartita de la Caja de Herramientas permite articular los ejes temáticos disponiendo para la comprensión de la Independencia como proceso histórico la Parte I; la comprensión del presente a partir del análisis diacrónico en la Parte II y la concientización identitaria de un accionar conjunto y colectivo de toda la población salvadoreña en la Parte III.

En total se diseñaron 20 herramientas didácticas que tienen unas características comunes. Las actividades tienen autonomía entre sí, es decir, que no tienen una secuencia encadenada. Por otra parte, todas incluyen la relación del contenido con el programa de estudios oficial del Ministerio de Educación, incluso pueden incorporarse como parte de este contenido, ampliación de este o una revisión diacrónica del mismo. Tienen una duración no demasiado extensa (máximo 3 horas-clase, aunque algunos cuentan con una preparación ex aula). Asimismo, incluyen todos los recursos necesarios para ser desarrolladas y que estén dispuestos, de forma que sea fácilmente reproducibles, ya sean estos documentos, cartas, fotografías, tablas, fragmentos de libros, mapas etc. Además de instrumentos de evaluación y propuestas de adaptación curricular.

En este sentido, está en consonancia con el enfoque socioformativo de las competencias, el cual propone que el estudiantado debe abordar las situaciones de forma práctica, a partir de los contenidos declarativos y conceptuales con un compromiso ético. (Tobón, 2010, pp. 11-12). Y, además, garantiza una metodología activa que implica

las motivaciones, los conocimientos y experiencias de los y las estudiantes; sus ritmos y formas de aprendizaje, la diversidad y la inclusión de todos y todas, el trabajo colaborativo y solidario, la heterogenidad, las relaciones pre-existentes, el respeto y la progresiva autonomía que hay que ir fomentando, el sentido, la expresión, la opinión alternativa, las expectativas, el diálogo, el acuerdo y también los disensos. (Martini \& Pérez, 2018, p. 156) 


\begin{tabular}{|l|l|l|l|}
\hline \multicolumn{4}{|c|}{ CAJA DE HERRAMIENTAS DIDÁCTICAS 200 AÑOS EN TUS MANOS } \\
PARTE I. LA INDEPENDENCIA \\
\hline $\begin{array}{l}\text { Unidades } \\
\text { Didácticas }\end{array}$ & Ejes temáticos & Herramienta didáctica & $\begin{array}{l}\text { Habilidades fundamen- } \\
\text { tales que desarrolla }\end{array}$ \\
\hline \multirow{3}{*}{ Independencia } & Procesos políticos & $\begin{array}{l}1.1 \text { Independencia en } \\
\text { WhatsApp }\end{array}$ & Actividad declarativa \\
\cline { 2 - 4 } & Configuración social & 1.2 ¿Quién es quién? & $\begin{array}{l}\text { Actividad identificación } \\
\text { y comparación }\end{array}$ \\
\cline { 2 - 4 } & Contexto económico & 1.3 Juego del comercio & $\begin{array}{l}\text { Actividad lúdica y } \\
\text { vivencial }\end{array}$ \\
\cline { 2 - 4 } & $\begin{array}{l}\text { Significado y } \\
\text { trascendencia }\end{array}$ & $\begin{array}{l}1.4 \text { Detectives de la } \\
\text { historia }\end{array}$ & $\begin{array}{l}\text { Actividad de síntesis/ } \\
\text { adquisición de técnicas } \\
\text { profesionales }\end{array}$ \\
\hline
\end{tabular}

Nota: Tomado de Córdoba, Ramírez \& Viegas, 2019, p. 18.

\section{Secuencia didáctica de cada herramienta}

La secuencia didáctica de cada herramienta está diseñada para que estén, a disposición de la persona formadora, todos los elementos necesarios para su puesta en práctica. De esta manera, se les ofrecen los recursos organizados y secuenciados para el uso con el estudiantado, así como información relevante que garantice el conocimiento de principales datos y enfoques, también sugerencias de lecturas más específicas. Se incluye, además, una secuenciación de pasos a seguir así como instrumentos de evaluación para ser aplicados en el tiempo propuesto.

A continuación, se exponen las herramientas propuestas, así como su correspondencia con la metodología planteada.

\begin{tabular}{|c|c|c|c|}
\hline \multicolumn{4}{|c|}{$\begin{array}{l}\text { CAJA DE HERRAMIENTAS DIDÁCTICAS } 200 \text { AÑOS EN TUS MANOS } \\
\text { PARTE II. } 200 \text { AÑOS DE HISTORIA }\end{array}$} \\
\hline $\begin{array}{l}\text { Unidades } \\
\text { didácticas }\end{array}$ & Ejes temáticos & $\begin{array}{l}\text { Herramienta } \\
\text { didáctica }\end{array}$ & $\begin{array}{l}\text { Habilidades fundamen- } \\
\text { tales que desarrolla }\end{array}$ \\
\hline \multirow{3}{*}{$\begin{array}{l}\text { Procesos } \\
\text { políticos }\end{array}$} & El Estado & 2.1 Ultra crisis & Juego lúdico. Reflexión. \\
\hline & Ciudadanía/derechos & $\begin{array}{l}2.2 \text { Trazos de } \\
\text { ciudadanía }\end{array}$ & Actividad empática \\
\hline & $\begin{array}{l}\text { Conflictividad/ } \\
\text { acuerdo }\end{array}$ & 2.3 Ucronía & Actividad reflexiva \\
\hline \multirow[t]{4}{*}{$\begin{array}{l}\text { Procesos } \\
\text { sociales }\end{array}$} & $\begin{array}{l}\text { Desigualdad } \\
\text { socioeconómica }\end{array}$ & $\begin{array}{l}2.4 \text { Cuentos de } \\
\text { historia }\end{array}$ & $\begin{array}{l}\text { Actividad lúdica/ } \\
\text { aplicación/arte }\end{array}$ \\
\hline & Mujeres & $\begin{array}{l}2.5 \text { Selfis de la } \\
\text { historia }\end{array}$ & $\begin{array}{l}\text { Aplicación de } \\
\text { contenidos/empatía }\end{array}$ \\
\hline & Etnicidad & $\begin{array}{l}\text { 2.6 Festival de } \\
\text { máscaras }\end{array}$ & Empatía/reflexión \\
\hline & Demografía & $\begin{array}{l}2.7 \text { Mi familia } \\
\text { tiene historia }\end{array}$ & $\begin{array}{l}\text { Actividad de síntesis/ } \\
\text { adquisición de técnicas } \\
\text { profesionales }\end{array}$ \\
\hline \multirow[t]{4}{*}{$\begin{array}{l}\text { Procesos } \\
\text { económicos }\end{array}$} & $\begin{array}{l}\text { Agricultura de } \\
\text { exportación }\end{array}$ & \multirow{4}{*}{$\begin{array}{l}\text { 2.8 Stop motion } \\
\text { histórico }\end{array}$} & \multirow{4}{*}{$\begin{array}{l}\text { Actividad de síntesis/ } \\
\text { arte }\end{array}$} \\
\hline & Industria (ISI) & & \\
\hline & $\begin{array}{l}\text { Servicios y } \\
\text { neoliberalismo }\end{array}$ & & \\
\hline & Medio ambiente & & \\
\hline \multirow[t]{4}{*}{$\begin{array}{l}\text { Procesos } \\
\text { culturales }\end{array}$} & Patrimonio & $\begin{array}{l}2.9 \text { Museo en el } \\
\text { aula }\end{array}$ & Actividad reflexiva/arte \\
\hline & Localidad & $\begin{array}{l}2.10 \text { Imágenes } \\
\text { de mi comunidad }\end{array}$ & $\begin{array}{l}\text { Actividad investigación/ } \\
\text { proyecto comunitario }\end{array}$ \\
\hline & Religiosidad & $\begin{array}{l}2.11 \text { Gráfico en } \\
\text { vivo }\end{array}$ & $\begin{array}{l}\text { Actividad de adquisi- } \\
\text { ción de técnicas profe- } \\
\text { sionales/reflexiva }\end{array}$ \\
\hline & Expresiones artísticas & $\begin{array}{l}2.12 \text { Historia en } \\
\text { movimiento }\end{array}$ & $\begin{array}{l}\text { Actividad de aplicación/ } \\
\text { Arte }\end{array}$ \\
\hline
\end{tabular}

Nota: Tomado de Córdoba, Ramírez \& Viegas, 2019, p. 18

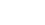


No contamos con el espacio suficiente para la descripción de la totalidad de las herramientas didácticas; sin embargo, a modo de ejemplificación e ilustración de la metodología se describen de forma breve cuatro de ellas.

- $\quad$ 1.3. Juego del comercio. Actividad lúdica y vivencial. Actividad correspondiente a la Parte I, donde se desarrollan herramientas para comprender el proceso de Independencia. Esta actividad didáctica es un juego de estrategia donde los equipos experimentan las condiciones económicas del momento, a partir de la compra y venta de mercancías. El juego está diseñado de forma que se simulan las condiciones económicas de los diferentes actores en el Reino de Guatemala entre sí y con el otro lado del Atlántico.

- 2.1. Ultra crisis. Juego y reflexión. Actividad correspondiente a la Parte II de la Caja de Herramientas. Está basada en los "serious games" donde el estudiantado, dividido en equipos, plantea una nueva sociedad para resolver los principales problemas de supervivencia a una catástrofe. Al final se reflexiona acerca de las soluciones planteadas, a la luz de los tipos de Estados existentes y las problemáticas que debe resolver un gobierno, en relación con las situaciones históricas que ha resuelto o no el Estado salvadoreño a lo largo de su historia. Se realiza una revisión histórica de los tipos de Estado en El Salvador.

\begin{tabular}{|c|c|c|c|}
\hline \multicolumn{4}{|c|}{$\begin{array}{l}\text { CAJA DE HERRAMIENTAS DIDÁCTICAS } 200 \text { AÑOS EN TUS MANOS } \\
\text { PARTE III. TRICENTENARIO }\end{array}$} \\
\hline $\begin{array}{l}\text { Unidades } \\
\text { didácticas }\end{array}$ & Ejes temáticos & Herramienta didáctica & $\begin{array}{l}\text { Habilidades fundamentales que } \\
\text { desarrolla }\end{array}$ \\
\hline \multirow[t]{4}{*}{ Tricentenario } & & $\begin{array}{l}\text { 3.1 Comunidad de } \\
\text { talentos }\end{array}$ & Actividad cooperativa \\
\hline & & 3.2 Concursos de arte & Actividad artística \\
\hline & & $\begin{array}{l}\text { 3.3 Cartas para el } \\
\text { futuro }\end{array}$ & Actividad reflexiva \\
\hline & & $\begin{array}{l}\text { 3.4 Cápsula del } \\
\text { tiempo }\end{array}$ & Actividad reflexiva \\
\hline
\end{tabular}

Nota: Tomado de Córdoba, Ramírez \& Viegas, 2019, p. 19.

- 2.5. Selfis de la historia. Aplicación de contenidos/empatía. Actividad correspondiente a la Parte II. En diferentes momentos históricos las mujeres han tenido una vida distinta a la actual y a su vez, similar. El estudiantado, dividido en grupos, debe interpretar la situación de un período concreto de la historia de las mujeres en El Salvador, a partir de textos e imágenes diversas. Con ello, los equipos deben expresar sus conclusiones acerca de fotografías dramatizadas simulando vestimenta, peinados, espacios, técnica fotográfica. Se aprovechan y estimulan los conocimientos de edición de imágenes, de dramatización, a la par del análisis crítico de fuentes primarias y de síntesis.

- 3.3. Cartas para el futuro. Actividad reflexiva. Esta dinámica corresponde a la Parte III donde al estudiantado se le plantea una conciencia del transcurso del tiempo, de la continuidad histórica y de la asunción de responsabilidades cívicas. En esta herramienta el estudiantado recibe una carta del pasado, de sus bisabuelos generacionales, narrándoles el entorno de El Salvador del momento y 
sus esperanzas en un prometedor futuro. Con esta información, se les propone escribir cartas a sus descendientes generacionales para la celebración del futuro Tricentenario. La actividad implica una reflexión de las apuestas a futuro, de las acciones individuales y colectivas para la construcción conjunta de la sociedad salvadoreña, dentro de cien años.

\section{Puesta en práctica de Caja de Herramientas Didácticas}

Se pusieron en práctica dos de las herramientas didácticas, con una selección de estudiantes de Tercer Ciclo y Bachillerato, que tuvo como resultado las siguientes evidencias.

Como parte de la innovación didáctica se propuso practicar dos de las herramientas didácticas:

- Herramienta 1.3. llamada El juego del comercio

- Herramienta 2.1 llamada Ultra crisis

- $\quad$ La puesta en práctica se realizó en diciembre de 2019, cuando el calendario escolar salvadoreño había finalizado, ya que su jornalización es de febrero a octubre. De forma tal, que se practicaron en un espacio de enseñanza formal bilingüe, con un estudiantado reducido y una selección de estudiantes de Tercer Ciclo y Bachillerato $^{6}$

Se escogieron estas herramientas didácticas puesto que representaban, en parte, la esencia metodológica de la Caja de Herramientas, se podían realizar en una mañana ambas y por su complejidad (en especial, El juego del comercio) necesitaban de una práctica para su ajuste.

Los resultados fueron muy satisfactorios, en diferentes sentidos. Acá enlistamos los principales aportes:

Jugar en el ámbito de la asignatura de Estudios Sociales es posible y, además, necesario. Son muchas las propuestas actuales acerca de la ludificación del aula, justificado en el sentido de una apertura emotiva

6 Agradecemos al Colegio Bilingüe Livingstone y, en especial a su directora Licenciada Alejandra Labbe de Ábrego, por su colaboración y al grupo de estudiantes que participaron en la práctica de las herramientas didácticas.

y una mejora en el aprendizaje. Ambas herramientas didácticas están basadas en el juego.

- $\quad$ Aprendizaje por descubrimiento: fundamentalmente en la herramienta de El juego del comercio, el grupo de estudiantes explicaba, desde la experiencia de un intercambio condicionado por las mismas reglas y normas históricas del siglo XVIII, las conclusiones a las que llegan especialistas en historia de la economía, sin las lecturas realizadas. Es un verdadero juego de roles.

La evaluación de la jornada, por parte del grupo de estudiantes recogió algunas ideas que reafirmaron el uso de metodologías participativas, ya que las y los adolescentes participantes reconocieron que al presentar la jornada e indicar que el trabajo iba a ser en relación a la historia se desmotivaron y lo asociaron al tedio, que insistieron, significa para ellos las clases de Estudios Sociales. Sin embargo, consideraron excelente la metodología de aprendizaje y concluyeron que así les gustaría que se enseñara la historia, y los demás contenidos de la materia de Estudios Sociales.

\section{Conclusiones}

Es así, que para la sociedad salvadoreña del siglo XXI, en las vísperas de celebrar 200 años de ese acontecimiento que allanaría la ruta a la conformación de lo que hoy se conoce como El Salvador, 1821 es mucho más que una fecha conmemorativa de vítores a "héroes pasados", es una oportunidad para repensar la historia de doscientos años plagada de aciertos y desaciertos, de éxitos, alegrías y llantos, de esperanzas, revoluciones, reformas, emprendimientos, guerras, masacres, luchas desigualdades, cooperaciones, proyectos, anhelos, trabajos, invisibilidades, reivindicaciones, acuerdos y derechos alcanzados.

El 2021 nos presenta la encrucijada de aprender de un pasado cuyas hebras configuran la sociedad actual salvadoreña y que se enfilan hacia el futuro.

Situar en el centro a las niñas, los niños y adolescentes y en él, el centro de su aprendizaje de las competencias cívicas e históricas permite 
repensar, revalorizar y resignificar la historia nacional, solo así el Bicentenario de la Independencia Centroamericana trascenderá de una mera fecha de celebración patria, a un auténtico hito de reflexión y crítica, que haga replantear hacia dónde se conduce El Salvador, como nación, como Estado y como sociedad, en donde todos sus integrantes participen en la construcción de un futuro más próspero y justo, y en donde cada uno de ellos pueda llegar a valorar su papel en esa construcción.

\section{Bibliografía}

Ayala, E. Ideas, estrategias y experiencias para la innovación en formación ciudadana (2018). En Ramis, A. \& Rodríguez, C (comp.). Educación y democracia: Formación ciudadana para la escuela de hoy, (pp. 167-201). San Salvador: INFOD.

Córdoba, K., Ramírez, V. \& Viegas, J. (2019). Caja de Herramientas Didáctica Bicentenario: Doscientos años en tus manos. Manuscrito presentado para su publicación

Ferro, M. (1993). Como se cuenta la historia a los niños del mundo entero. Buenos Aires: FCE.

González, L. \& Avelar, M. (2019). ¿Quiénes son los formadores de docentes en El Salvador? Condiciones educativas y sociales. San Salvador: Instituto Nacional de Formación Docente-Ministerio de Educación.

Gómez, C., Ortuño, J. \& Molina, S. (2014). "Aprender a pensar históricamente Retos para la historia en el siglo XXI". Tempo e Argumento 6(11), 5-27. https://www.redalyc.org/pdf/33181/338131531002.pdf.

Informe de rendición de cuentas del proyecto "Formación de Especialistas y docentes de primero y segundo ciclos de educación básica en las cuatro asignaturas básicas del currículo nacional” 2016. (2017). San Salvador: Universidad Centroamericana José Simeón Cañas. https://noticias.uca.edu.sv/uploads/ texto_4767/file/PDF-771319-1502375743-598c6f3f50d56.pdf.

Iturrate, G., Bardavio, A., Bou, N. \& Pérez, X. (1996). Les fonts en les ciéncies socials Instruments per a l'estudi de les societats. Barcelona: Graó.

Martini, G. \& Pérez, M. (2018). "Convivencia, inclusión y enfoque de derechos”. En Ramis, A. \& Rodríguez, C. Educación y democracia: Formación ciudadana para la escuela de hoy (comp.), (pp. 111-165). San Salvador: INFOD.

Memoria de labores de Ministerio de Educación de 2018-2019. (2019). San Salvador: DPI. https://www.transparencia.gob.sv/institutions/mined/documents/ memorias-de-labores.
Memoria de labores de Ministerio de Educación de junio 2019 a mayo 2020. (2020). San Salvador: DPI. https://www.transparencia.gob.sv/institutions/mined/ documents/memorias-de-labores.

Memoria histórica y cultura de paz. Experiencias en América Latina. (2006). Lima: InWent, DED, MIMDES

Ramírez-Barat., C. (2018). Ciudadanía, memoria y cultura de paz en El Salvador. Caja de Herramientas para docentes y educadores. San Salvador: Auschwitz Institute for Peace and Reconciliation. Ministerio de Educación de El Salvador. Procuraduría para la Defensa de los Derechos Humanos de E Salvador. http://www.auschwitzinstitute.org/es/ciudadania-memoria-y-cultura-de-paz-en-el-salvador-caja-de-herramientas-para-docentes-y-educadores/.

Ramis, A. \& Rodríguez, C. (2018). Educación y democracia: Formación ciudadana para la escuela de hoy. San Salvador: INFOD.

Rosa, A. (2004). «Memoria, historia e identidad. Una reflexión sobre el papel de la enseñanza de la historia en el desarrollo de la ciudadanía»>. En Carretero, M. \& Voss, J. (comp.). Aprender y pensar la historia, (pp. 47-70). Buenos Aires: Amorrortu. http://rubenama.com/articulos/Rosa_rivero_memoria_identidad.pdf.

Tobón, S., Pimienta, J \& García, J. (2010). Secuencias didácticas: aprendizaje y evaluación de competencias. México: Pearson Educación. http://files.ctezona141.webnode.mx/200000004-8ed038fca3/secuencias-didacticastobon-120521222400-phpapp02.pdf

UNESCO. Actas de la Conferencia General. 30 a reunión de la Unesco, v. 1: Resoluciones (2000), París: Unesco. https://unesdoc.unesco.org/ark:/48223 pf0000119216_spa?posInSet=3\&queryId=N-EXPLORE-54e3fc62-cf29-43 $75-\operatorname{ad} 22-83413 \mathrm{~d} 2 \mathrm{c} 185 \mathrm{f}$

Valle, A., Núñez, J., Rodríguez, S. \& González-Pumariega, S. (2002). "La motivación académica”. En González-Pienda, J., González, R., Núñez, J. \& Valle, A. (coord.). Manual de Psicología de la Educación. (117- 144). Madrid: Editorial Pirámide.

\section{Entrevistas}

AE. 15 años. 9. ${ }^{\circ}$

AR. 13 años. $7 .^{\circ}$

BB. 10 años. . $^{\circ}$ 
Carlos Rodríguez, coordinador del INFOD (Instituto Nacional de Formación Docente) y Director Nacional de Formación Docente, ambas instancias del Ministerio de Educación.

CD. 11 años. $6^{\circ}$

DD. 9 años. $3 .^{\circ}$

DH. 16 años. 1. ${ }^{\circ}$ Bachillerato

Dr. Héctor Lindo-Fuentes. Profesor Emérito de Historia y Estudios Latinoamericanos en la Universidad de Fordham, Nueva York

Dra. Xiomara Avendaño Rojas. Doctora en Historia, docente investigadora Universidad de El Salvador. Dra. Eugenia López. Doctora en Historia, docente investigadora de la Universidad de El Salvador.

EE. 11 años. 5 .

EP. 9 años. 3 . $^{\circ}$

FD. 12 años. $6^{\circ}$

GB. 13 años. $7 .^{\circ}$

JL. 13 años. $7 .^{\circ}$

KD. 13 años. $7^{\circ}$

LD. 12 años. $6^{\circ}$

Lcdo. Leonel Hernández, Licenciatura en Historia por la Universidad de El Salvador. Profesor de Historia de la Universidad Centroamericana "José Simeón Cañas".

MD. 7 años. $2 .^{\circ}$

Miguel Ángel Aguilar, Técnico I Depto. De Currículo, Educación Media del Ministerio de Educación. Eric Doradea Director Nacional de Bibliotecas, Archivos y Publicaciones del Ministerio de Educación.

ML. 13 años. $7 .^{\circ}$

MS. 11 años. $5 .^{\circ}$

MSc. Alfredo Ramírez. Máster en Historia por la Universidad de Indiana, coordinador de la Licenciatura en Historia de la Universidad de El Salvador.

MZ. 10 años. 5. $^{\circ}$

NP. 17 años. 2..$^{\circ}$ Bachillerato

NH. 15 años. $1 .{ }^{\circ}$ Bachillerato

RH. 13 años 7..$^{\circ}$

SP. 13 años $7 .^{\circ}$

SR. 10 años. $5^{\circ}$

VR. 17 años. $2 .^{\circ}$ Bachillerato

VT. 12 años. $6^{\circ}$ 